\title{
Mapeamento de competências na construção civil: um estudo aplicado ao canteiro de obras
}

O tema deste estudo busca por meio do mapeamento de competências na construção civil, analisar os conhecimentos, habilidade e atitudes em um canteiro de obras. O artigo teve como objetivo mapear as competências dos cargos no canteiro de obras em uma organização da construção civil no município de Chapecó (SC), para a aplicabilidade da gestão por competências. O procedimento metodológico adotado buscou, por meio de entrevistas, coletar dados que possam subsidiar o mapeamento das competências definindo os papéis e os cargos acerca dos conhecimentos, habilidades e atitudes desejadas pela organização. As principais constatações do estudo surgem no momento em que o mapeamento estabelece a competência em situação, ou seja, posta em ação, explicando como ocorre no canteiro de obras. Conforme foram estabelecidas as atribuições dos cargos e funções na coleta de dados demonstrou a fragilidade ficando baixo do desejável nas competências em saber agir, ou seja, as atitudes.

Palavras-chave: Competências; Mapeamento; Construção civil.

\section{Mapping skills in construction: an applied study the construction site}

The subject of this technical study is the issue of mapping skills in construction, by analyzing the knowledge, skills and attitudes in a construction site. The article aims to map the competencies of positions at the construction site in a building in the city of Chapecó (SC), for the applicability of competency management. The methodological procedure adopted sought through interviews, collecting data that can help the mapping of competencies that define the roles and positions on the knowledge, skills and attitudes desired by the organization. The main conclusions of the study come at a time when the mapping establishes the competence situation, ie put into action, explaining occurs as in the construction site The duties of the positions and functions were established in data collection demonstrated the fragility getting below the desirable skills in knowing how to act, attitudes.

Keywords: Competence; Mapping; Construction.

Topic: Construções e Arquitetura Sustentáveis

Reviewed anonymously in the process of blind peer.
Received: 19/12/2019

Approved: 22/03/2020
Anderson Saccol Ferreira (iD)

Universidade do Oeste de Santa Catarina, Brasil

http://lattes.cnpq.br/4850843904897537

http://orcid.org/0000-0003-1541-0953

anderson.ferreira@unoesc.edu.br
Referencing this:

FERREIRA, A. S.. Mapeamento de competências na construção civil: um estudo aplicado ao canteiro de obras. Environmental Scientiae, v.2, n.1, p.1-15, 2020. DOI: http://doi.org/10.6008/CBPC26746492.2020.001.0001 


\section{INTRODUÇÃO}

O tema mapeamento de competências na construção civil demonstra em seu contexto uma análise acerca de um canteiro de obras, tendo como foco as competências, habilidades e atitudes necessárias para realizar respectivas tarefas conforme a função do colaborador. $O$ estudo traz um levantamento de dados acerca da realidade da organização e dos colaboradores, por meio do mapeamento das competências requeridas da empresa.

Dessa forma, a problemática surgiu pela observação da não avaliação sistemática dos colaboradores pela organização, conforme a competência requerida para as funções que eles exercem na empresa. Tornando necessário adotar estratégias para mapear as funções e suas atribuições acerca dos conhecimentos, habilidades e atitudes dos colaboradores dentro da organização. A pesquisa teve como objetivo mapear as competências dos cargos no canteiro de obras em uma organização da construção civil no município de Chapecó (SC), para a aplicabilidade da gestão por competências.

O procedimento metodológico adotado buscou fazer uma análise do contexto em que os colaboradores estão inseridos por meio da biografia, experiência profissional e escolaridade, para que após pudéssemos analisar o saber fazer, saber ser e saber agir. Em um segundo momento, efetuaram-se entrevistas semiestruturadas, o qual compõe o mapeamento das competências técnicas e atitudes. Ainda se destaca que o mapeamento das competências passa a definir os papéis e os cargos e, principalmente, o conhecimento, habilidades e atitudes desejadas pela organização.

Como resultados o estudo demonstrou contribuir para organização, pois o mapeamento mostrou as fragilidades, os pontos positivos e negativos e onde deve ser implantado as estratégias de melhoramento das funções dos colaboradores. Também podemos ressaltar que o estudo demonstrou fragilidades no saber agir e atitudes dos colaboradores, bem como, as interferências que podem ser ocasionadas no trabalho em equipe que acarretam na produtividade e no comprometimento do trabalho.

Este artigo está estruturado pela contextualização da organização, a realidade investigada que dá suporte literário ao embasamento do estudo. Na sequência o estudo apresenta os procedimentos metodológicos adotados e posteriormente remete ao mapeamento das competências na organização, demonstrando as atividades conhecimento e habilidades desejáveis conforme o cargo e função. Por último, o estudo demonstra o mapeamento da gestão por competência na organização, onde se dirige a prospeç̧ão e soluções, pontos fortes e fracos e as recomendações para o corrigir as fragilidades e ampliar as potencialidades da organização encerrando com as considerações finais do estudo.

\section{REVISÃO TEÓRICA}

\section{O contexto da organização}

Este estudo técnico analisa uma organização do ramo da construção civil, presente no município de Chapecó (SC), fundada em 2009 com o propósito de adotar modelo de gestão integrada, aliando projeto e construção de forma prática, minimizando custos e criando formas arquitetônicas diferenciadas. O escopo 
da organização estudada está em fornecer atividades relacionadas a projetos arquitetônicos e incorporação de empreendimentos imobiliários. Para tal a empresa implantou o Programa Brasileiro de Qualidade Produtiva no Habitat (PBQP-H) atendendo os requisitos do nível A. Conta com uma equipe de 25 colaboradores, sendo 21 colaboradores ligados diretamente ao canteiro de obras e quatro ao setor administrativo da empresa.

O organograma geral da empresa estabelece a hierarquia e a vinculação entre a diretoria e cargos. As atividades desenvolvidas, acerca dos níveis de autoridade, responsabilidade e participação de cada uma das funções estão definidas no diagrama dos processos estabelecidos pela empresa conforme a Figura 1.

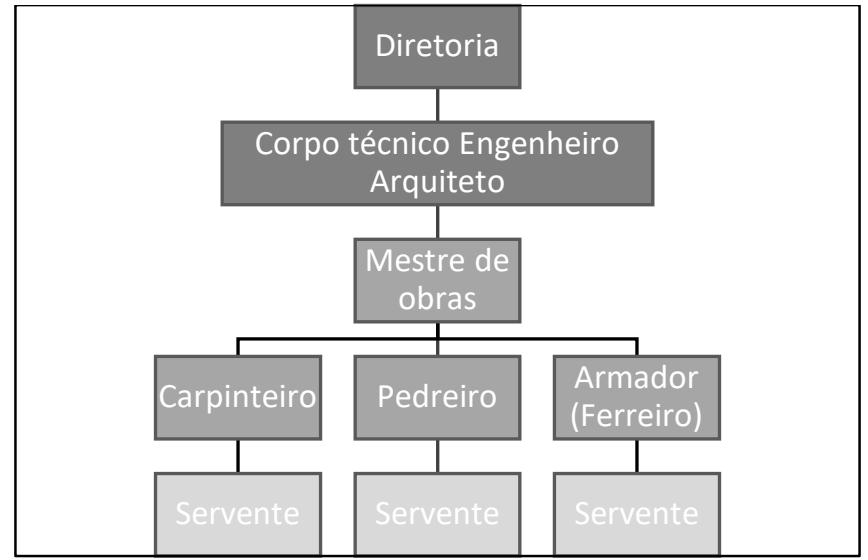

Figura 1: Diagrama dos processos estabelecidos pela empresa

Os processos estão definidos conforme hierarquia, sendo a diretoria e o administrativo com funções de gestão, seguida do corpo técnico e o operacional. O mestre de obras segue como gestor operacional, é ele quem coordena todas as atividades relacionadas às obras. Já o armador, o carpinteiro e o pedreiro, executam as funções operacionais designadas e o servente auxilia ambas as funções com o intuito de agilizar a obra, sendo que todos estão subordinados a equipe técnica e à diretoria da empresa.

O mapeamento por competências ocorreu no contexto em que os colaboradores atuam, ou seja, dentro da obra, tendo como ambiente interno as atividades exercidas na execução de edificações, estando relacionando com as atividades de qualificação e treinamentos que o colaborador irá adquirindo ao longo de sua carreira. As competências dos colaboradores tornam-se uma ferramenta fundamental para gerencial os recursos, sendo importante analisar o contexto em que a equipe de trabalho está submetida, para que os níveis de exigências tenham coerência com meio em que eles estão inseridos.

\section{A realidade investigada}

Nas últimas duas décadas, devido ao processo de globalização e desenvolvimento tecnológico, muitas profissões sofreram mudanças, outras foram extintas, no entanto na construção civil, as tarefas permanecem as mesmas que seus antecedentes executavam. Apesar de toda a tecnologia encontrada no mercado, algumas tarefas são praticamente artesanais, como as formas para concreto, as armaduras, o levantamento de alvenaria. Nem todas as tecnologias são acessíveis, por isto muita das atividades continuam sendo artesanais e algumas herdadas de pai para filho, assim, muitos ocupam funções apenas pela 
experiência prática, sem ter, em muitos casos, o ensino fundamental completo.

Segundo Cordeiro et al. (2002), na construção civil se empregam "trabalhadores com baixa escolaridade, pois esse é um setor em que, ainda, para começar a trabalhar, não é preciso ser alfabetizado nem conhecer a profissão". Como em algumas empresas há necessidade de cursos específicos para operar um equipamento ou realizar uma tarefa, na construção civil acredita-se que basta iniciar como servente e observar os colegas realizando as tarefas. Contudo, o nível de escolaridade pode afetar as práticas da construção civil, por isto, levantou-se o grau de escolaridade na empresa pesquisada.

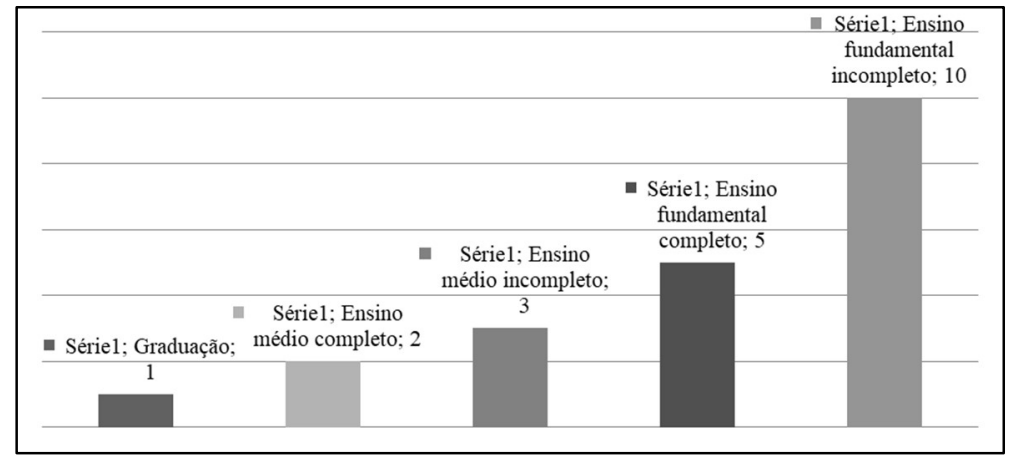

Figura 2: Nível de escolaridade dos colaboradores da empresa.

A Figura 2 demonstra o baixo nível de escolaridade dos colaboradores, sendo $50 \%$ dos colaboradores com nível fundamental incompleto e $10 \%$ com o ensino médio completo sendo que $5 \%$ com graduação, nesse caso podemos destacar que o cargo necessita, pois o mesmo é o responsável técnico da obra, e por possuir um órgão regulamentado necessita de profissional graduando na área.

Já a Figura 3 é possível observar, como contraponto, que, cerca de $60 \%$ dos colaboradores da empresa possuem mais de 10 anos de experiência profissional comprovada, e $25 \%$ entre 5 a 10 anos de experiência, ou seja, 85\% dos colaboradores possuem mais de 5 anos de experiência profissional. Ressaltase ainda, que muitos dos colaboradores da empresa iniciaram suas atividades na construção civil ainda muito jovens, desenvolvendo habilidades com familiares que já trabalhavam na construção civil.

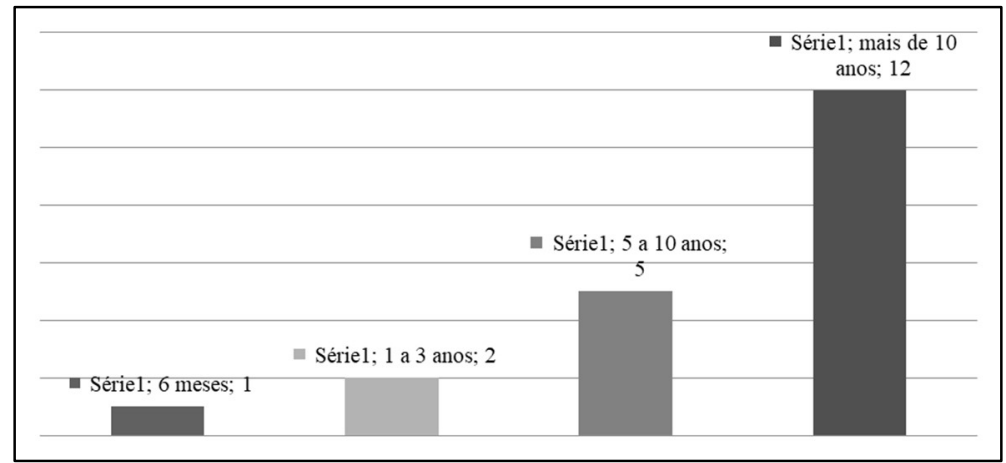

Figura 3: Tempo de experiência profissional.

A competência deverá estar compatível com a função, tanto em escolaridade quanto na obtenção da prática. Portanto, considera-se que a competência está no termo em que qualifica o colaborador a realizar sua atividade com maestria, ou seja, estar apto a função realizando-a com conhecimento, habilidade e atitude, na literatura como atributos da competência (BRANDÃO et al., 1999). Nesse contexto em que 
colaboradores da organização estão inseridos, surge à situação problema da pesquisa, quais estratégias devem ser adotadas para mapear a gestão por competência dos cargos na empresa.

Dessa forma, necessita-se entender quais são as atribuições de cada função dentro do contexto, isto é, quais são as funções de cada colaborador, pois elas serão o ponto de partida para mapear as competências essências. A Tabela 1 descreve quais são os papéis que os colaboradores desempenham dentro da empresa.

Tabela 1: Papéis desempenhados pelos colaboradores da empresa.

\begin{tabular}{|l|l|}
\hline Papéis & Descrição \\
\hline $\begin{array}{l}\text { Mestre de } \\
\text { obras }\end{array}$ & $\begin{array}{l}\text { Supervisionar as equipes de trabalhadores controlando os recursos produtivos da obra tais como arranjos físicos, } \\
\text { equipamentos, materiais, insumos e equipes de trabalho, bem como, administrar o cronograma da execução de } \\
\text { obra. }\end{array}$ \\
\hline Armador & $\begin{array}{l}\text { Responsável em cortar, dobrar e montar as armaduras de aço para estruturas de concreto armado, preparar a } \\
\text { confeç̧ão de armações para estruturas de concreto. }\end{array}$ \\
\hline Carpinteiro & $\begin{array}{l}\text { Responsável em planejar os trabalhos de carpintaria tais como, preparar o canteiro de obras, montar e desmontar } \\
\text { formas de madeira para estrutura em concreto armado, preparar andaimes e guarda-corpo, bem como, demarcar } \\
\text { a locação e marcação da obra. }\end{array}$ \\
\hline Pedreiro & $\begin{array}{l}\text { Responsável em organizar o local de trabalho, construir estruturas em alvenaria, revestimentos, contrapiso } \\
\text { estruturas e fundações em concreto armado. }\end{array}$ \\
\hline Servente & $\begin{array}{l}\text { Responsável por auxiliar os serviços gerais no canteiro de obras, tais como, auxiliar o armador, carpinteiro, } \\
\text { pedreiro, preparar argamassa, concreto e limpeza do canteiro de obras. }\end{array}$ \\
\hline
\end{tabular}

Segundo Le Boterf (2003) "não há competência senão posta em ação; a competência só pode ser competência em situação". Dessa forma, a Tabela 1 explica as três dimensões da competência, o saber fazer, o saber e o saber ser, isto é, habilidades, conhecimento e atitudes. Assim, o ser competente se torna uma consequência da utilização adequada dos seus atributos de competência (AMARAL, 2006). Dessa forma, o saber fazer torna-se o grau mais elementar da competência, isto é, a capacidade do indivíduo de realizar algo como armar ferragens, montar e desmontar formas de concreto ou executar o levantamento de alvenaria, observar e interpretar mobilizando suas habilidades (LE BOTERF, 2003).

Já o saber agir está na atitude não reduzindo apenas ao saber fazer, mas em saber operar, ou seja, não é necessário ser competente para realizar o que é prescrito ou para aplicar o que já é conhecido. O saber agir é ir além, consiste em antecipar o incidente (LEITE et al., 2006). Nesse caso passa a ser uma habilidade do gestor da equipe, ou seja, o mestre de obras deverá possui a capacidade de mobilizar suas habilidades, conhecimentos e atitudes para solucionar determinados problemas (LE BOTERF, 2003).

Le Boterf (2003) destaca três eixos que formam a competência do indivíduo, a biografia ou o meio em que eles estão inseridos, experiência profissional e formação educacional, esse último conforme demonstramos na Figura 2, a formação educacional é muito baixa, porém a experiência profissional é alta conforme demonstrado na Figura 3. Para atingir a competência nos mais variados papéis de se tornar necessário que os três eixos resultem em o saber agir, o querer agir e o poder agir. Segundo Le Boterf (2003), o saber agir, compete o meio em que o profissional deve não apenas saber executar a tarefa, mas dever ir além do que está prescrito. Já o querer agir está na motivação do indivíduo em querer ou não querer realizar esta tarefa, ou até mesmo realizar o saber agir. Porém, o poder agir está na relação ou situação profissional em que ele pode assumir responsabilidades e riscos dentro do contexto da organização (LE BOTERF, 2003).

Pressupõe-se que o saber agir passa a ser: os recursos necessários, o processo, o querer agir a motivação do indivíduo. A combinação de recursos para realizar determinada situação e o poder agir dá a 
legitimidade da ação, o modo de agir e as formas de trabalhar (LE BOTERF, 2003). A competência consiste em saber combinar os recursos de saberes, saber-fazer, aptidões, qualidades pessoais e experiências em relação aos objetivos visados (LE BOTERF, 2003), isto é, o colaborador deverá combinar os recursos, mas as competências devem ser estabelecidas pelas organizações postas em ações. A noção de competência deve ter uma construção individual na empresa (BITENCOURT et al., 2010).

Assim, as organizações que levam a prescrever o seu próprio trabalho passam a ter mais espaço, pois inserem as combinações dos recursos e passam a desenvolver processos participativos, contratos por objetivo, formas de auto avaliações e o enfraquecimento das funções de controle ou de autoridade em proveito das funções de facilitação, ou seja, ao adotar o gerenciamento constroem a lógica da competência, passando a ser toda a arquitetura social que sustenta a articulação entre trabalho e formação (DUTRA, 2004). A competência pode estar associada não apenas às pessoas, mas às equipes de trabalho na organização, ou seja, cada equipe de trabalho pode manifestar uma competência coletiva (LE BOTERF, 2003).

Nesse sentido a gestão por competências propõem orientar esforços para planejar, captar, desenvolver e avaliar o indivíduo, grupal e organizacional, as competências necessárias à consecução de seus objetivos (BRANDÃO et al., 2001). Portanto, a gestão por competência se torna um processo continuo que se perpetua pela formação da estratégia da organização, missão, valores de futuro, indicadores de desempenho e metas com base nos objetivos estratégicos (CARBONE et al., 2005). Dessa forma, a aplicação dos conhecimentos, habilidades e atitudes dos colaboradores na organização passa gerar um desempenho profissional, que por sua vez são expressados pelos comportamentos e consequências que os colaboradores manifestam, gerando assim os resultados, isto é, o desempenho do colaborador representa, uma expressão de sua competência (BRANDÃO et al., 2001).

\section{METODOLOGIA}

O procedimento metodológico do estudo parte da análise do contexto em que os colaboradores estão inseridos, ou seja, biografia, experiência profissional e formação educacional, acerca da análise do saber fazer, saber ser e saber agir. O mapeamento das competências passa a definir os papéis e os cargos acerca dos conhecimentos, habilidades e atitudes desejadas na organização.

Adotamos a coleta de dados por meio de entrevistas semiestruturadas que buscaram captar a experiência dos sujeitos ouvidos como uma totalidade, em que diferentes eventos relatados por eles podem ser predominantes, buscando compreender padrões de experiências na medida em que elas emergem (THOMPSON et al., 1989). Para Triviños (1995) a semiestruturada é "aquela que parte de certos questionamentos básicos [...]" ou seja, oferece diversas interrogativas, produto de novas hipóteses que vão surgindo à medida que as respostas do entrevistado são recebidas (TRIVIÑOS, 1995). Dessa forma, as entrevistas ocorreram entre os dias 25 maio a 30 de agosto de 2017, sendo entrevistados 21 colaboradores da organização.

Para compor o procedimento de coleta de dados buscou-se realizar mapeamento de competência técnicas e atitudes, isto é, avaliação das competências requeridas por um superior hierárquico e por um 
ocupante do cargo. Assim, a avaliação foi feita pela escolha de ocupante do cargo de forma intencional, levando em consideração a experiência e objetividade por ele demonstrada, sendo que o conteúdo do mapa foi resultado de decisão consensual entre o superior hierárquico e trabalhador entrevistados.

Já para a avaliação de competências técnicas, a avaliação das competências requeridas foi feita pelo ocupante do cargo, pelo superior hierárquico do ocupante do cargo, por um colega de trabalho que conheça o ocupante do cargo e um subordinado do ocupante do cargo. Os avaliadores foram selecionados de forma aleatória e o ocupante do cargo e o seu superior hierárquico são escolhidos intencionalmente. As avaliações foram feitas separadamente sendo que todas as avaliações mantiveram o anonimato no momento de preparar este texto. A lista de competências técnicas conhecimento habilidades e atitudes são explicitadas na Tabela 3.

As figuras demonstram as notas assinaladas de 0 a 4 o nível de domínio sobre cada conhecimento, habilidade e atitude do ocupante do cargo. Dessa forma, são extraídos dos valores positivos e negativos que servirão para um feedback ao colaborador. Portanto o gestor poderá identificar quais as competências técnicas e quais as atitudes estão em falta podendo melhorar os processos seletivos e os programas de qualificação e de reconhecimento pessoal dos colaboradores.

\section{RESULTADOS E DISCUSSÃO}

\section{Mapeamento das competências na organização}

A situação problema vivida pela organização perpetuava na forma em que a gestão estava sendo conduzida, pois não se tinham descrito os papéis e tão pouco a descrição das atividades, apenas o colaborador exercia a função em que estava designado. Nesse sentido, a empresa passa por uma situação contraditória, de um lado exerce as atribuições do programa de qualidade produtiva (PBQP-H) sem designar coerentemente nenhuma definição das atribuições e papéis dos colaboradores com competências indefinidas para cada cargo.

Dessa forma, ao traçar os objetivos estratégicos proporcionamos ao gestor um processo avaliativo diferenciado, onde os papéis e atribuições dos colaboradores ficam claras, de forma a facilitar a análise das competências acerca dos conhecimentos, habilidades e as atitudes, tanto do indivíduo quanto do grupo, isto é, o mapeamento e o diagnóstico contribuem para gestão do grupo com diferentes competências e objetivo em comum. Para iniciar a implantação do sistema de gestão por competências, fez-se necessário extrair dados documentados pela organização para subsidiar as competências requeridas, como apresentado na Tabela 2.

Tabela 2: Mapeamento de competências.

\begin{tabular}{|l|l|l|}
\hline Ação & Fonte de informação & Procedimento \\
\hline $\begin{array}{l}\text { Documentos da organização com as } \\
\text { competências estabelecidas para } \\
\text { alcançar as metas estratégicas }\end{array}$ & $\begin{array}{l}\text { Discurso dos dirigentes com } \\
\text { contribuição do planejamento } \\
\text { estratégico da organização. }\end{array}$ & $\begin{array}{l}\text { Elaboração dos conhecimentos habilidades e } \\
\text { atitudes do grupo }\end{array}$ \\
\hline $\begin{array}{l}\text { Definição do cargo e perfil da } \\
\text { organização }\end{array}$ & $\begin{array}{l}\text { Setor de desenvolvimento Humano } \\
\text { DH }\end{array}$ & Programa da folha DH \\
\hline Preenchimento do mapa de & Setor de DH da organização; & Preenchimento de fichas coma competência dos \\
\hline
\end{tabular}




\begin{tabular}{|l|l|l|}
\hline $\begin{array}{l}\text { competências técnicas essenciais } \\
\text { para o cargo dentro da organização }\end{array}$ & hierarquia e descrição dos cargos. & $\begin{array}{l}\text { cargos levando em conta das ações que a } \\
\text { organização pretende implantar. }\end{array}$ \\
\hline Mapa de atitudes para cada cargo & $\begin{array}{l}\text { Superior hierárquico e um } \\
\text { colaborador que atue no cargo em } \\
\text { análise }\end{array}$ & $\begin{array}{l}\text { A escolha do colaborador deve levar em } \\
\text { consideração a experiência, isenção e } \\
\text { objetividade. }\end{array}$ \\
\hline $\begin{array}{l}\text { Realização das avaliações das } \\
\text { competências técnicas evidenciadas } \\
\text { em cada cargo }\end{array}$ & $\begin{array}{l}\text { O ocupante do cargo, um superior } \\
\text { hierárquico, um colega do ocupante } \\
\text { do cargo, e um subordinado }\end{array}$ & $\begin{array}{l}\text { Todas as avaliações foram mantidas o seu } \\
\text { anonimato sendo que cada avaliador fez } \\
\text { separadamente. O método de escolha do colega } \\
\text { foi aleatório. }\end{array}$ \\
\hline $\begin{array}{l}\text { Realização de avaliação das atitudes } \\
\text { possuídas pelos ocupantes do cargo }\end{array}$ & $\begin{array}{l}\text { O ocupante do cargo, um superior } \\
\text { hierárquico, um colega do ocupante } \\
\text { do cargo, e um subordinado }\end{array}$ & $\begin{array}{l}\text { Todas as avaliações foram mantidas o seu } \\
\text { anonimato sendo que cada avaliador fez } \\
\text { separadamente. O método de escolha do colega } \\
\text { foi aleatório }\end{array}$ \\
\hline $\begin{array}{l}\text { Identificar discrepâncias positivas e } \\
\text { negativas entre competências atuais } \\
\text { e desejadas }\end{array}$ & Setor de $\mathrm{DH}$ & - \\
\hline $\begin{array}{l}\text { Feedback positivo e negativo com } \\
\text { informações ao superior hierárquico } \\
\text { e ao ocupante do cargo; }\end{array}$ & Setor de $\mathrm{DH}$ & - \\
\hline
\end{tabular}

Segundo Albuquerque et al. (2001), o mapeamento das competências consiste na elucidação das competências, em que os cargos da empresa são avaliados por indicadores de competências que reunidos por semelhança passam a converter nas competências. Além disso, contribui para facilitar a compreensão do conceito de competência aos membros da equipe, referenciando a formação da visão de como as competências se relacionam com o exercício dos papéis na organização (AMARAL, 2006).

Nesse sentido, a elaboração do glossário de atributos que definem o mapeamento das competências técnicas essenciais dos cargos da organização passa a ser elaborado sob as diretrizes da organização levando em consideração as ações que a organização pretende implantar. A Tabela 3 compõe os conhecimentos, habilidades e atitudes do colaborador como indivíduo e seu comportamento em equipe.

Tabela 3: Glossário de competências, habilidades e atitudes requeridas pela organização.

\begin{tabular}{|l|l|l|}
\hline Conhecimento & Habilidades & Atitudes \\
\hline Interpretação do desenho técnico & Aprender com as experiências do grupo & Agilidade \\
Métodos de construção & Apresentação de resultados positivos & Confiabilidade \\
Métodos e técnicas para uso de & Curiosidade \\
ferramentas & Resolução de problemas & Ética \\
Domínio das técnicas construtivas & Trabalho em equipe & Segurança \\
& Habilidade dentro da função (apresentar resultados com & Organização \\
& rapidez) & Pontualidade \\
& Visão global & Produtividade \\
& Controle dos recursos produtivos & Comprometimento \\
& Administração do canteiro de obras e dos insumos & Respeitar Hierarquia \\
& & Iniciativa \\
Autocrítica \\
autocontrole
\end{tabular}

Fonte: Amaral (2006).

O glossário de atributos das competências requeridas pela organização corresponde a uma descrição das atribuições que a organização requer dos seus colaboradores. Ele permite uma visão dos atributos da equipe, de forma que todos os membros possam compreender seu significado. Com o glossário torna possível elaborar a tabela de conhecimentos e habilidades para cada função, ou seja, cada cargo da organização passa a ter suas atribuições conforme o nível hierárquico. Na Tabela 4 é possível identificar o cargo e o conhecimento e habilidades requeridas pela organização. 
Tabela 4: Conhecimento e habilidades conforme o cargo dentro da organização.

\begin{tabular}{|c|c|}
\hline Cargo & Conhecimentos e habilidades \\
\hline $\begin{array}{ll}\text { Mestre de } \\
\text { Obras }\end{array}$ & $\begin{array}{l}\text { 1. Conhecimento técnico em projetos arquitetônicos, elétricos, estruturais e hidrossanitários. } \\
\text { 2. Saber supervisionar equipes de trabalhos no canteiro de obras } \\
\text { 3. Saber controlar os recursos produtivos das obras (arranjos físicos, equipamentos, materiais, insumos e } \\
\text { equipes de trabalho) } \\
\text { 4. Saber administrar o cronograma da obra. } \\
\text { 5. Saber interagir e atuar em equipe } \\
\text { 6. Ser responsável } \\
\text { 7. Respeitar a hierarquia } \\
\text { 8. Saber liderar equipes de trabalho } \\
\text { 9. Saber repassar as informações aos auxiliares } \\
\text { 10. Ter noções de segurança do trabalho }\end{array}$ \\
\hline Armador & $\begin{array}{l}\text { 1. Conhecimento técnico em projetos estruturais } \\
\text { 2. Conhecer armaduras, bitolas de ferragem } \\
\text { 3. Ler projetos estruturais e arquitetônicos } \\
\text { 4. Saber dobras, cortar e armar ferragem } \\
\text { 5. Saber interagir e atuar em equipe } \\
\text { 6. Ser responsável } \\
\text { 7. Saber respeitar a hierarquia } \\
\text { 8. Ter iniciativa } \\
\text { 9. Saber repassar as informações aos auxiliares } \\
\text { 10. Possuir habilidades manuais }\end{array}$ \\
\hline Carpinteiro & $\begin{array}{l}\text { 1. Conhecimento técnico em projetos estruturais e arquitetônicos } \\
\text { 2. Saber planejar trabalhos de carpintaria } \\
\text { 3. Sabe conferir, montar e desmontar formas em madeira } \\
\text { 4. Saber preparar canteiro de obras } \\
\text { 5. Saber interagir e atuar em equipe } \\
\text { 6. Ser responsável } \\
\text { 7. Saber respeitar a hierarquia } \\
\text { 8. Ter iniciativa } \\
\text { 9. Saber repassar as informações aos auxiliares } \\
\text { 10.Possuir habilidades manuais }\end{array}$ \\
\hline Pedreiro & $\begin{array}{l}\text { 1. Conhecimento técnico em projetos arquitetônicos } \\
\text { 2. Saber organizar e preparar o local de trabalho na obra } \\
\text { 3. Saber construir estruturas e alvenaria } \\
\text { 4. Saber construir revestimentos e contrapiso } \\
\text { 5. Saber interagir e atuar em equipe } \\
\text { 6. Ser responsável } \\
\text { 7. Saber respeitar a hierarquia } \\
\text { 8. Ter iniciativa } \\
\text { 9. Saber repassar as informações aos auxiliares } \\
\text { 10. Possuir habilidades manuais }\end{array}$ \\
\hline Servente & $\begin{array}{l}\text { 1. Saber auxiliar nos serviços gerais do canteiro de obras } \\
\text { 2. Conhecer traço de massas e concreto } \\
\text { 3. Comprometimento com a empresa } \\
\text { 4. Conhecer as noções básicas de segurança no trabalho } \\
\text { 5. Saber interagir e atuar em equipe } \\
\text { 6. Ser responsável } \\
\text { 7. Saber respeitar a hierarquia } \\
\text { 8. Ter iniciativa } \\
\text { 9. Ser organizado } \\
\text { 10. Ter autocrítica e autocontrole }\end{array}$ \\
\hline
\end{tabular}

A Tabela 4 segue a hierarquia do canteiro de obras, conforme está demonstrado no diagrama dos processos estabelecidos pela organização. Dessa forma, o mestre de obras está posicionado como a função principal no canteiro de obras. O carpinteiro, armador e pedreiro desempenham atribuições hierarquicamente iguais, porém cada profissional é responsável pela execução de atividades especificas, enquanto o servente ocupa o mais baixo cargo hierárquico dentro da organização. 


\section{Mapeamento da gestão por competência na organização}

A gestão por competência se trata de um modelo dinâmico tomando como referência a estratégia da organização para direcionar as ações de recrutamento, seleção, treinamento e formação, gestão de carreira, desempenho e estabelecimento de parcerias para o desenvolvimento das competências necessárias, buscando alcançar os objetivos estratégicos da empresa (SILVA, 2003). Dessa forma, os colaboradores devem desempenhar competências necessárias buscando a produtividade para desempenhar as funções em que são submetidos. Nesse caso, o conhecimento, habilidades e atitudes devem ser mensuradas dentro do desejável pela organização.

O mapeamento das competências analisadas deve identificar pessoas com o potencial de crescimento, flexibilidade para enfrentar incidentes críticos a demanda da empresa. Nesse contexto, mapeamos o nível do conhecimento e habilidades conforme o cargo dentro da organização, ou seja, os cargos de mestre de obras, armador, carpinteiro, pedreiro, servente que incorporam a operacionalização do canteiro de obras. Para tanto, o cargo de mestre de obras exige habilidades e conhecimentos específicos, pois sua função supervisiona as equipes de trabalhadores controlando os recursos de produtividade da obra, tais como arranjos físicos, equipamentos, materiais, insumos, equipes de trabalho e administrar o cronograma da execução de obra. Estes são os conhecimentos necessários para atingir a competência desejável dentro da função demonstrada na Figura 4.

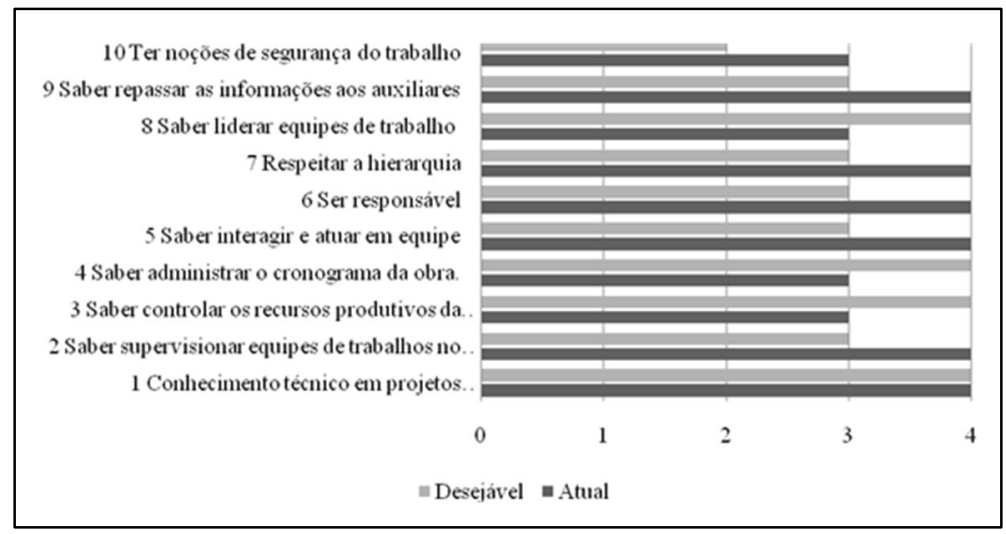

Figura 4: Elaborado com dados coletados pelas fichas de avaliação de competências.

Os indicadores, saber controlar os recursos produtivos das obras, saber administrar o cronograma da obra, saber liderar equipes de trabalho estão a baixo dos esperados pela organização, estes indicadores demonstram o conhecimento e habilidade do mestre de obras na empresa. Nesse aspecto é possível melhorar o seu desempenho com treinamentos focadas na liderança e produtividade podendo melhorar este desempenho, os itens 3 e 4 impactam diretamente na questão financeira da obra, já o item 8 impacta diretamente no relacionamento entre a equipe de trabalho. Em contrapartida, os itens, saber supervisionar equipes de trabalhos no canteiro de obras, saber interagir e atuar em equipe, ser responsável, respeitar a hierarquia, saber repassar as informações aos auxiliares e ter noções de segurança do trabalho o desempenho atual estão acima do desejável pela organização.

Já o cargo de Armador descreve como suas atribuições preparar a confecção de armaduras de aço, 
corte, dobra e montagem de estruturas de concreto armado. Nessa, cargo os colaboradores necessitam conhecimento e habilidade técnica especifica para desempenhar a função, conforme mostra a avaliação das competências técnicas na Figura 5.

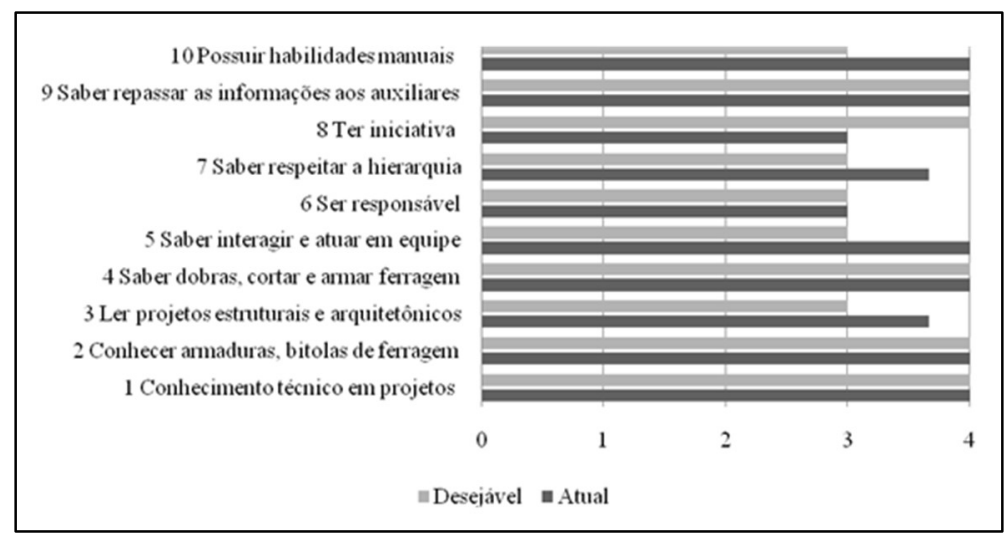

Figura 5: Elaborado com dados coletados pelas fichas de avaliação de competências técnicas.

Os colaboradores ficam dentro do desejável pela organização, apenas no o item, ter iniciativa está abaixo do desejável. Porém nas competências que remetem ao conhecimento e habilidade desdenham um resultado positivo estando acima do desejável pela organização. Nesse caso, a atitude ter iniciativa deverá ser trabalhado para que o colaborador possa desenvolver esta atribuição.

O cargo de Carpinteiro estabelece conhecimento e habilidades cujos trabalhadores devem planejar o canteiro de obras, a montagem das formas de madeira para as estruturas em concreto amado, preparar os andaimes e demarcar a locação da obra. A Figura 6 destaca a avaliação das competências técnicas desejáveis pela organização para esta função.

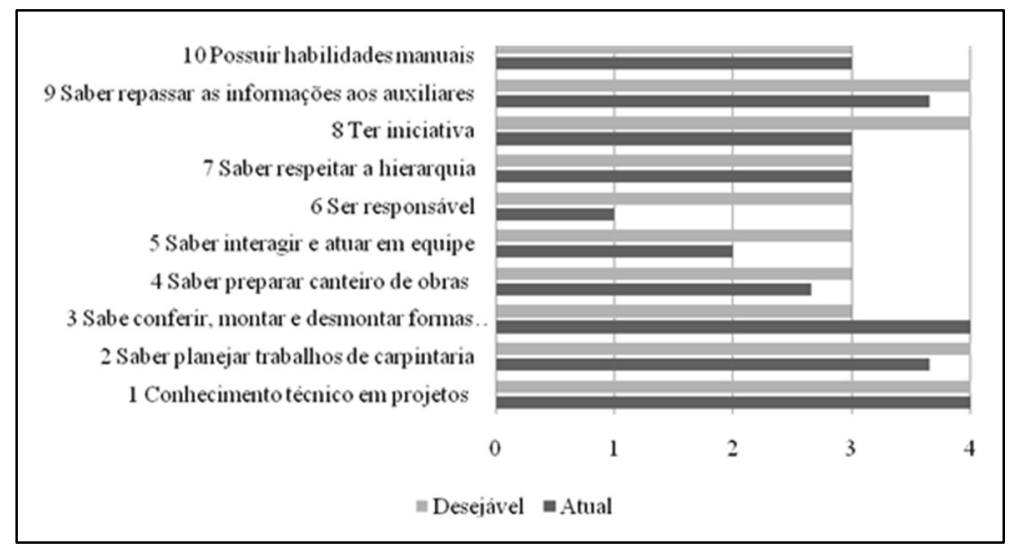

Figura 6: Elaborado com dados coletados pelas fichas de avaliação de competências técnicas.

Os conhecimentos e habilidades em quase todos os itens atingem o desejável, porém as atitudes ficam abaixo do desejável, isto é, os itens, ser responsáveis, saber interagir e atuar em equipe e ter iniciativa fica muito a baixo do desejável. Dessa forma, para elevar estes indicadores recomenda-se que a organização desenvolva ações voltadas para o melhor desempenho das atitudes.

Para o cargo de pedreiro a empresa estabelece as habilidades e conhecimentos requeridos para a função que são descritas em construir estruturas em alvenaria, revestimento, contrapiso, estruturas em concreto armado e organizar o local de trabalho. Nesse sentido, a Figura 7 descreve a avaliação das 
competências desejáveis pela organização dos colaboradores que ocupam este cargo.

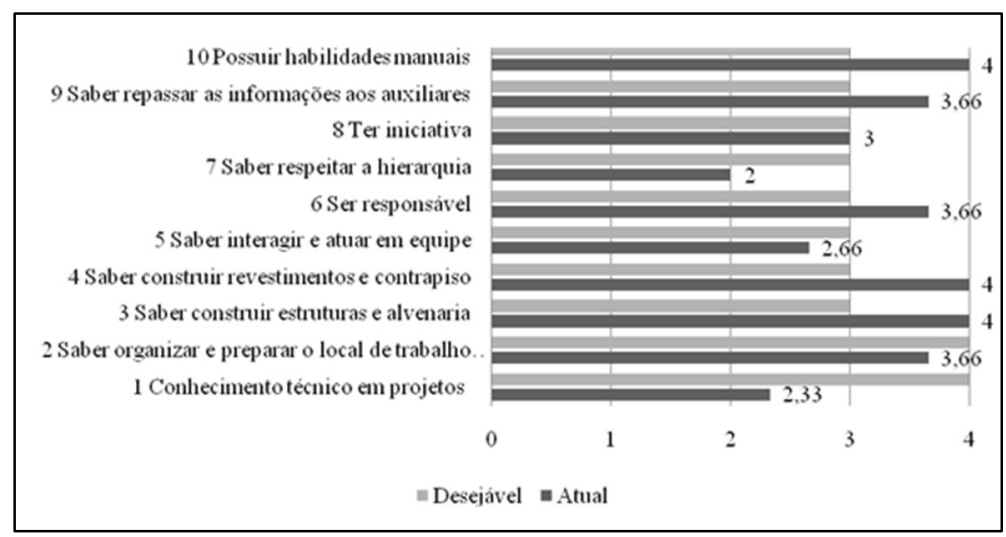

Figura 7: Elaborado com dados coletados pelas fichas de avaliação de competências técnicas.

O item 1 conhecimento técnico em projetos em que referência o conhecimento está bem abaixo do desejável, sendo que no item saber organizar e preparar o local de trabalho na obra em que se refere às habilidades e os itens, saber interagir e atuar em equipe, saber respeitar a hierarquia está a baixo de desejável, porém, quando referenciamos as habilidades e conhecimentos os itens 3 saber construir estruturas e alvenaria e saber construir revestimentos e contrapiso estão acima do desejável.

Estes dois itens são considerados os mais importantes pela organização, mas por outro lado, os demais itens podem influência no andamento e produtividade da função requerida. Assim, torna-se importante para esta função um desenvolver atividades ligadas às atitudes dos colaboradores para que os mesmos consigam atingir a competência que a organização estabelece. Já o cargo de servente é considerado o mais baixo na hierarquia da organização, suas funções remetem ao auxílio do armador, carpinteiro e pedreiro, bem como, preparar argamassa, concreto e limpeza do canteiro de obras, é uma das funções que não exige nenhum grau de experiência.

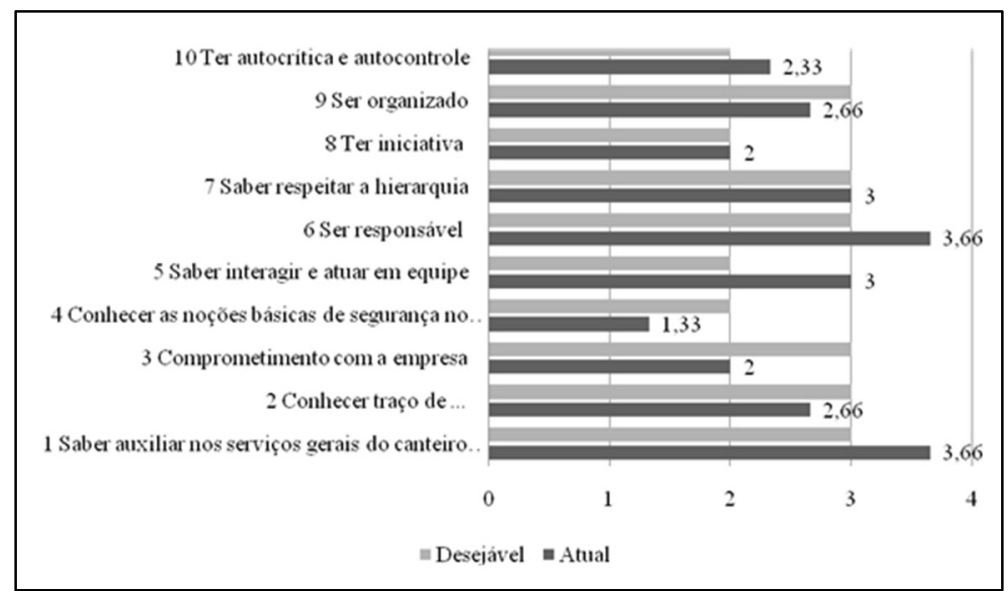

Figura 8: Elaborado com dados coletados pelas fichas de avaliação de competências técnicas.

Está função demonstrou atingir o índice desejável, isto se dá por ser um cargo que não necessita possuir experiência nas atividades técnicas, por outro lado, nos itens compromisso com a empresa e saber atuar em equipe, demonstrou um indicador abaixo do desejável, este indicador pode ser melhorado com atividades que promovam o trabalho em equipe. 
Além da função de servente as outras quatro funções demonstraram na pesquisa pontos relevantes que podem ser melhoradas com o mapeamento das competências, as atribuições de cada função atingiram parcialmente o nível desejável pela organização, sendo que na maioria das atribuições que remetem aos conhecimentos, habilidades tiveram níveis desejáveis, pois estas atividades remetem aos trabalhos práticos, já as atribuições que remetem as atitudes ficam a baixo do desejável. Dessa forma, a competência não estaria apenas no estado de formação profissional ou em um conjunto de conhecimentos adquiridos ou de capacidades aprendidas, mas estaria na mobilização e aplicação de conhecimentos e capacidades em uma situação especifica em que o indivíduo deveria apresentar recursos e restrições próprias a esta situação (LE BOTERF, 2003).

Segundo Amaral (2006) "a competência está associada à ação tais como saber o que faz para julgar, escolher e decidir, mobilizar recursos de pessoas, financeiros e materiais criando sinergia entre eles", isto é, compreender de forma a transmitir informações e conhecimentos assegurando o entendimento da mensagem, trabalhando o conhecimento acerca de novos modelos mentais e que promovam o desenvolvimento dos outros, bem como, ter responsabilidades e comprometimentos com os objetivos da organização, assumindo ricos e consequências de suas ações e ser reconhecido (AMARAL, 2006). Nesse contexto, a competência passa a ser formada pela inteligência posta em prática de situações que está apoiada nos conhecimentos adquiridos transformando com mais força quando maior for à complexidade da situação (ZARIFIAN, 2001). Assim, a competência passa a ser a capacidade da pessoa assumir iniciativas indo além das atividades prescritas, sendo capazes de compreender e dominar as novas situações em que elas são submetidas, ou seja, a fragilidade da organização pesquisada está no saber agir, atitude, pois a competência não pode ser reduzida apenas no saber operar e no saber fazer, mas sim a necessidade de antecipar, o saber ir além (LEITE et al., 2006).

Outro ponto relevante está associado à competência não apenas da pessoa, mas da equipe de trabalho, nesse caso envolve todos os cargos. Portanto, a atitude pode influenciar na competência coletiva, pois alguns pontos em que envolvem a produtividade, comprometimento o trabalho em equipe, iniciativa do indivíduo quando não destacado influencia na relação da equipe não manifestando a competência coletiva (LE BOTERF, 2003). Dessa forma, os resultados nos mostram um ponto fundamental onde a organização deverá agir. O mapeamento das competências manifestada nesta análise demonstra resultados pertinentes dos pontos fortes que estão no conhecimento e habilidades, desenvolvidos pela experiência que o cargo exige, porém como ponto fraco as atitudes desmontaram resultados a baixo do desejável, sendo que, algumas medidas trabalhadas acerca das formas de explorar as atitudes do indivíduo podem resultar na competência coletiva da organização.

\section{CONCLUSÕES}

O artigo teve como objetivo mapear as competências dos cargos no canteiro de obras em uma organização da construção civil no município de Chapecó-SC, para a aplicabilidade da gestão por competências. Dessa forma, com a análise dos dados tornou-se possível alcançar o objetivo proposto, pois 
o artigo retrata a definição dos papéis e o mapeamento de cada cargo respectivo dentro do canteiro de obras.

As principais constatações do estudo surgem no momento em que o mapeamento estabelece a competência em situação, ou seja, posta em ação, explicado como ocorre dentro da organização o saber fazer, o saber ser e o saber agir, ou seja, conhecimentos, habilidades e as atitudes. Conforme foram estabelecidas as atribuições dos cargos e funções na coleta de dados demonstrou a fragilidade ficando baixo do desejável nas competências em saber agir, ou seja, as atitudes. O estudo demonstrou como contribuição para organização o mapeamento das fragilidades, os pontos positivos e negativos, e onde devem ser implantadas estratégias para o melhoramento das funções principalmente no saber agir atitudes dos colaborardes.

As limitações do estudo surgem na dificuldade de levantar os dados primeiramente pela baixa escolaridade da equipe operacional, bem como, pelos obstáculos gerados pelo entendimento das suas atribuições. Outro ponto relevante na limitação do estudo se restringe apenas nos colaboradores da organização, deixando de fora as equipes terceirizadas como o encanador, eletricista e pintor. A escolha do estudo de caso se deu pelas fragilidades que contemplam a construção civil, principalmente no canteiro de obras, diante muitas vezes de mão-de-obra com baixa escolaridade ou sem conhecer a profissão. Desse modo, este estudo passa a ser considerado especial por se tratar de uma atividade que pouco discutido no meio acadêmico, principalmente quando análise das competências está ligada as atividades práticas, que muitos julgam em apenas saber realizá-las, ou seja, o saber fazer.

As recomendações futuras para o estudo surgem na perspectiva de ampliar o estudo abordando não apenas os cargos operacionais, mas sim o setor técnico e o setor administrativo da empresa, confrontando com os resultados deste estudo para verificar se a mesma competência em situação, saber fazer, saber ser e saber agir ocorre com as mesmas características nos outros setores da empresa. Também, ampliar o estudo mapeando mais de uma organização em diferentes municípios, analisando suas similaridade e discrepâncias. Por fim, fica como sugestão a implementação da pesquisa e a implantação do mapeamento da gestão por competência dentro da organização de forma a contribuir por melhores resultados, aperfeiçoando a comunicação e consolidação dos conceitos da competência na organização.

\section{REFERÊNCIAS}

ALBUQUERQUE, L. G.; OLIVEIRA, P. M.. A gestão de estratégica de pessoas. Caderno de Pesquisas em Administração, São Paulo, v.8, n.4, p.13-25, 2001.

AMARAL, R. M.. Desenvolvimento e aplicação de um método para o mapeamento de competências em inteligência competitiva. Mestrado (Dissertação) Universidade Federal de São Carlos, São Carlos, 2006.

BITENCOURT, C. C.; BARBOSA, A. C. Q.. Gestão de competências: articulando indivíduos, organizações e sociedade. Gestão contemporânea de pessoas. 2 ed. Porto Alegre: Bookman, 2010.

BRANDÃO, H. P.; GUIMARÃES, T.. A gestão de competências e gestão de desempenho: tecnologias distintas ou instrumentos de um mesmo construto?. Revista de Administração de Empresas, v.41, n.1, p.8-15, 1999.

BRANDÃO, H. P.; GUIMARÃES, T. A.; BORGES-ANDRADE, J. E.. Competências profissionais relevantes à qualidade no atendimento bancário. Revista de Administração Pública, v.35, n.6, p.61-81, 2001.

CARBONE, P. P.; BRANDÃO, H. P.; LEITE, J. B. D.. Gestão por competências e gestão do conhecimento. Rio de Janeiro: FGV, 2005.

CORDEIRO, C. C.; MACHADO, I. M.. O perfil do operário da indústria da construção civil de Feira de Santa: Requisitos para uma qualificação profissional. Sitientibus, Feira de Santa, n.26, p.9-29, 2002. 
DUTRA, J. S.. Competências: conceitos e instrumentos para a gestão de pessoas na empresa moderna. São Paulo: Atlas, 2004.

LE BOTERF, G.. Desenvolvendo a competência dos profissionais. Porto Alegre: Artmed, 2003.

LEITE, I. C. B. B.; GODOY, A. S.; ANTONELLO, C. S.. O aprendizado da função gerencial: os gerentes como atores e autores do seu processo de desenvolvimento. Revista Aletheia, n.23, p.27- 41, 2006.

SILVA, S. M.. A gestão das competências organizacionais em empresas da cadeira de valor para provimento de telefonia celular de 3ạ Geração (3G). Mestrado (Dissertação em
Economia, Administração e Contabilidade) - Universidade Federal de São Paulo, São Paulo, 2003.

THOMPSON, C. J.; LOCANDER, W. B.; POLLIO, H. R.. Putting consumer experience back into consumer research: The philosophy and method of existential-phenomenology. Journal of Consumer Research, v.16, n.2, p.133-146, 1989.

TRIVIÑOS, A. N. S.. Introdução à pesquisa em ciências sociais: a pesquisa qualitativa em educação. São Paulo: Atlas, 1995.

ZARIFIAN, P.. Objetivo competência: por uma nova lógica. São Paulo: Atlas, 2001.

A CBPC - Companhia Brasileira de Produção Científica (CNPJ: 11.221.422/0001-03) detém os direitos materiais desta publicação. Os direitos referem-se à publicação do trabalho em qualquer parte do mundo, incluindo os direitos às renovações, expansões e disseminações da contribuição, bem como outros direitos subsidiários. Todos os trabalhos publicados eletronicamente poderão posteriormente ser publicados em coletâneas impressas sob coordenação da Cognitionis Publishing, da Companhia Brasileira de Produção Científica e seus parceiros autorizados. Os (as) autores (as) preservam os direitos autorais, mas não têm permissão para a publicação da contribuição em outro meio, impresso ou digital, em português ou em tradução. 